\title{
La adquisición de la terminología médica a través de la traducción (alemán-español)
}

\author{
Alba Montes Sánchez \\ Universidad de Córdoba \\ montessanchezalba@gmail.com \\ https://dx.doi.org.10.12795/futhark.2017.il2.05
}

Fecha de recepción: 21.09.2017

Fecha de aceptación: 12.11.2017

Resumen: El presente estudio pretende presentar un método para adquirir la terminología médica (DE-ES) a través de la traducción. Para ello, analizaremos las características propias del lenguaje biosanitario, así como los niveles de especialización a partir de distintos tipos de textos. Mediante el análisis terminológico y el estudio de los distintos errores posibles en la traducción alemán-español de textos seleccionados propondremos algunas medidas para subsanar dichos errores de traducción y para adquirir la terminología específica de este ámbito.

Palabras clave: terminología médica, errores de traducción, lengua general lenguajes de especialidad, tipos de textos.

\section{The acquisition of medical terminology through translation (German - Spanish)}

\begin{abstract}
This work has as main objective to present a method to acquire the medical terminology German-Spanish through the translation. In this study we will analyze the characteristics of the medical language, as well as the levels of specialization from different types of texts. By means of the terminological analysis and the study of the different possible errors in the German-Spanish translation of selected texts, we will propose some measures to correct these translation errors and to acquire the specific terminology of this field.
\end{abstract}

Key words: medical terminology, translation errors, general language, specialty languages, types of texts. 
Sumario: Introducción. I. El griego y el latín, fuentes del léxico biosanitario. 2. Tipos de textos. 3. Población de estudio y corpus textual. 3.I. Delimitación de la población de estudio. 3.2. Corpus textual. 4. Análisis: errores de traducción. 5. Resultados. 6. Propuesta metodológica para la traducción de textos biosanitarios. Conclusiones.

\section{Introducción}

El lenguaje especializado médico es uno de los lenguajes que mayor dificultad presenta en la actualidad, caracterizado principalmente por la evolución científica y técnica de la medicina y las numerosas modificaciones experimentadas. Se trata de un lenguaje distinto al lenguaje común, el cual requiere un alto grado de especialización, ya que actúa de puente entre el profesional sanitario que lo elabora y el destinatario del mismo. Es una labor compleja en la cual, además de poseer amplios conocimientos de Medicina, ha de dominar la gramática de la lengua origen (LO) y la lengua meta (LM) y atender a las constantes actualizaciones científicas.

Por otra parte, a pesar de que el sector biosanitario está conformado por un léxico elaborado y sofisticado, la relación entre sus textos establece lazos terminológicos entre todas sus ramas (Cabré 2000: 2):

[...] el traductor especializado no puede desempeñar su actividad profesional sin conocer la terminología del ámbito de especialidad al que pertenece el texto que traduce. [...] La traducción como práctica es un proceso de transferencia de información entre lenguas distintas en el que la terminología juega un papel relevante porque los especialistas, productores naturales del discurso especializado, utilizan habitualmente unidades terminológicas en los procesos de expresión y transferencia del conocimiento, porque todas las especialidades disponen de unidades terminológicas específicas que representan sus conceptos y porque las unidades que concentran con mayor densidad el conocimiento especializado son las unidades terminológicas [...] En consecuencia, la terminología es relevante en la práctica de la traducción especializada y es imprescindible que un traductor utilice terminología en sus textos.

Así, autores como Van Hoof (1986, 1999), López y Terrada (1990), Ordóñez y García (1989) afirman que el léxico especializado es exclusivamente el rasgo principal del lenguaje especializado médico, anteponiéndose a las particularidades sintácticas, morfológicas y estilísticas. Las principales características de este lenguaje son:

- Precisión: evitar términos vagos que no aportan datos precisos a la información (mucho, grande, rápido, caliente, prolongado, etc.), los vocablos 
rebuscados y el uso de extranjerismos innecesarios. Además, debe aclararse el significado de ciertos términos cuando no sean muy comunes.

- Claridad: omitir lenguaje figurado, transmitir ideas complejas con palabras y construcciones sencillas (reducir oraciones subordinadas) y emplear una sólida y adecuada estructura.

- Concisión: evitar mencionar datos irrelevantes, la repetición de las mismas ideas sin justificación y emplear enunciados afirmativos en lugar de la doble negación.

En su estudio sobre la terminología médica, Porep y Steudel (1974) señalan que el lenguaje médico alemán abarca cerca de 80000 nombres de medicamentos; 10000 palabras para designar partes del cuerpo, órganos y partes de órganos; 20 000 términos que se refieren a las funciones de los órganos y más de 60000 palabras para designar enfermedades. En total, nos enfrentamos aproximadamente a unos 500000 términos, tomando en consideración aquellos conceptos necesarios para la medicina y que están ligados a otras ramas complejas y especializadas, como la biología, psicología bioquímica, genética, etc.

En las páginas siguientes abordaremos el estudio del léxico biosanitario, así como la posibilidad de emplear la traducción para la adquisición del tecnolecto que lo sustenta. Para ello, elaboraremos un estudio sobre una población determinada, y en torno a textos médicos de distinto grado de dificultad.

\section{El griego y el latín, fuentes del léxico biosanitario}

Con respecto a la creación de conceptos sanitarios, afirma Santamaría (2009: 5), los griegos se vieron obligados a hacer uso del lenguaje cotidiano debido a la falta de un lenguaje especializado con una terminología, unas estructuras y un estilo específicos. En anatomía, por ejemplo, clasificaban las diferentes partes del cuerpo según su forma en instrumentos musicales (Wulff, 2004: 187). De esta forma, el griego se mantuvo como lengua primordial de la Medicina incluso en la gloriosa época del Imperio Romano. Los romanos tenían la posibilidad de usar la terminología griega, siendo estos su referencia, de forma que podrían distinguir su lenguaje cotidiano del lenguaje sanitario, convirtiéndolo así en terminología especializada. Más tarde, Aulo Cornelio Celso (Wulff, 2004: 187) exponía que el latín carecía de léxico para expresar los conocimientos que ya estaban denominados en griego, por lo que empleó varias técnicas e hizo que la terminología especializada griega sufriera una "latinización". Desde entonces, el griego y el latín han dominado la terminología médica, derivando de ambos idiomas gran parte de los términos médicos. De acuerdo con Fluck (1976): 
el lenguaje médico alemán se describe fundamentalmente por el alto número de vocablos de procedencia grecolatina, los cuales se encuentran complementados con la lengua general. Las fuertes raíces grecolatinas que caracterizan al lenguaje médico alemán suelen ser desconocidas por el hablante general, por lo que es necesario poseer un amplio conocimiento del vocabulario médico de raíz clásica.

Veamos algunos ejemplos:

\begin{tabular}{|l|l|l|}
\hline \multicolumn{1}{|c|}{ Término grecolatino } & \multicolumn{1}{c|}{ Término alemán } & \multicolumn{1}{c|}{ Término español } \\
\hline Geriatrie & Altersheilkunde & geriatría \\
\hline Ophtalmologie & Augenheilkunde & oftalmología \\
\hline Pädiatrie/ & Kinderheilkunde & pediatría \\
\hline Kardiologie & Herzheilkunde & cardiología \\
\hline
\end{tabular}

La construcción de un tecnicismo médico consta, por lo general, de un máximo de tres componentes: prefijo, sustantivo y sufijo. Suele suceder que haya presencia 0 influencia greco-latina en esta formación de palabras. De esta combinación de prefijos y sufijos, y raíces con origen grecolatino, nacen la mayor parte de los términos médicos que conocemos en la actualidad, lo que en cierta medida, contribuye a facilitar la traducción al español de los términos. A continuación ofrecemos algunos ejemplos de términos conformados por la unión con prefijos y sufijos:

\begin{tabular}{|l|l|l|l|}
\hline $\begin{array}{c}\text { Preffjo } \\
\text { (DE) }\end{array}$ & \multicolumn{1}{c}{ Término (DE) } & \multicolumn{1}{c|}{$\begin{array}{c}\text { Preffjo } \\
\text { (ES) }\end{array}$} & Término (ES) \\
\hline brachy- & Brachygraphie & braqui- & braquigrafía \\
\hline dys- & Dysmetrie & dis- & dismetría \\
\hline hemi- & Hemianop(s)ie & hemi- & hemianopsia \\
\hline makro- & makroskopisch & macro- & macroscópico \\
\hline mega- & Megalozephalie & mega- & megalocefalia \\
\hline mikro- & mikroskopisch & micro- & microscópico \\
\hline
\end{tabular}




\begin{tabular}{|l|l|l|l|}
\hline neo- & Neoplasie & neo- & neoplasia \\
\hline patho- & Pathogenese & pato- & $\begin{array}{l}\text { patogenia, } \\
\text { patogénesis }\end{array}$ \\
\hline skolio- & Skoliose & escolio- & escoliosis \\
\hline syn- & Syndrom & sín & síndrome \\
\hline sym- & Sympathikolytikum & sim- & simpaticolítico \\
\hline tachy- & Tachypnoe & taqui- & taquipnea \\
\hline thermo- & Therm(o)analgesimega & termo & termoanalgesia \\
\hline
\end{tabular}

\begin{tabular}{|l|l|l|l|}
\hline \multicolumn{1}{|c|}{$\begin{array}{c}\text { Suffjo } \\
\text { (DE) }\end{array}$} & \multicolumn{1}{|c|}{ Término (DE) } & -algia & proctalgia \\
\hline -algie & Proktalgie & -ectomía & gastrectomía \\
\hline -ektomie & Gastrektomie & -nóstico & $\begin{array}{l}\text { diagnóstico, } \\
\text { pronóstico }\end{array}$ \\
\hline -gnose & Diagnose, Prognose & faringitis \\
\hline -itis & Pharyngitis & -itis & fisiología \\
\hline -logie & Physiologie & -logía & carcinoma, mioma \\
\hline -om & Karzinom, Myom & -oma & artrosis, escoliosis \\
\hline -ose & Arthrose, Skoliose & -osis & endoscopia \\
\hline -skopie & Endoskopie & -oscopia & vasectomía \\
\hline -tomie & Vasektomie & -tomía & leucocitos \\
\hline -zyten & Leukozyten & -citos & \\
\hline
\end{tabular}

\section{Tipos de textos}

Numerosos autores han abordado el estudio de los géneros textuales de la Medicina a través de distintos tipos de documentos médicos o científicos, los cuales se pueden clasificar en función del público al cual van dirigidos. Cabe destacar, entre otras, la clasificación propuesta por Montalt i Resurrecció (2005): 


Futhark $12(2017)$
$45-70$




\begin{tabular}{|c|c|c|c|}
\hline Enfoque & Factor & \multicolumn{2}{|c|}{ Variable } \\
\hline \multirow[t]{8}{*}{ Comunicativo } & \multirow[t]{2}{*}{ Participantes } & \multicolumn{2}{|c|}{ 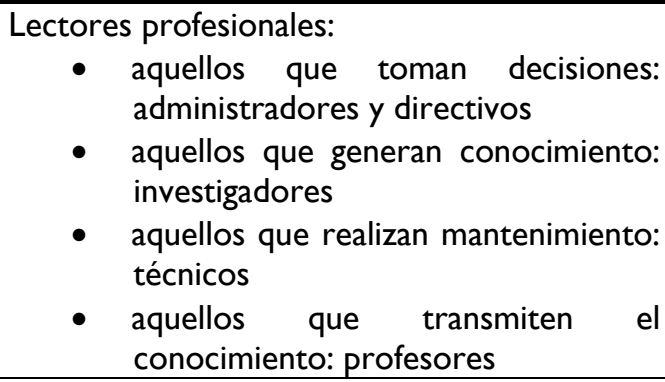 } \\
\hline & & \multicolumn{2}{|c|}{$\begin{array}{l}\text { Lectores no profesionales: } \\
\text { - aquellos que están en proceso de } \\
\text { aprendizaje: estudiantes } \\
\text { - aquellos interesados en la cultura } \\
\text { científica y técnica: lectores cultos } \\
\text { - aquellos que necesitan información } \\
\text { para resolver un problema (Ej. } \\
\text { instalar software, tomar un } \\
\text { medicamento): lectores domésticos }\end{array}$} \\
\hline & \multirow[t]{6}{*}{ Función social } & Géneros pedagógicos & $\begin{array}{l}\text { Facilitar procesos } \\
\text { pedagógicos }\end{array}$ \\
\hline & & Géneros divulgativos & $\begin{array}{l}\text { Difundir el } \\
\text { conocimiento técnico } \\
\text { y científico }\end{array}$ \\
\hline & & Géneros domésticos & $\begin{array}{l}\text { Facilitar ciertas tareas } \\
\text { domésticas }\end{array}$ \\
\hline & & $\begin{array}{l}\text { Géneros socio- } \\
\text { políticos }\end{array}$ & $\begin{array}{l}\text { Concienciar sobre } \\
\text { determinados temas }\end{array}$ \\
\hline & & Géneros publicitarios & $\begin{array}{l}\text { Comercializar } \\
\text { productos y servicios }\end{array}$ \\
\hline & & $\begin{array}{l}\text { Géneros } \\
\text { profesionales }\end{array}$ & $\begin{array}{l}\text { Facilitar } \\
\text { determinadas } \\
\text { actividades } \\
\text { profesionales }\end{array}$ \\
\hline
\end{tabular}




\begin{tabular}{|c|c|c|c|}
\hline & & \begin{tabular}{ll|} 
Géneros & de \\
investigación & \\
\end{tabular} & $\begin{array}{l}\text { Favorecer el avance } \\
\text { del conocimiento }\end{array}$ \\
\hline & $\begin{array}{l}\text { Propósito } \\
\text { retórico }\end{array}$ & $\begin{array}{l}\text { Instructivo } \\
\text { (exhortativo) }\end{array}$ & Dar instrucciones \\
\hline & & Expositivo & $\begin{array}{l}\text { Presentar } \\
\text { información }\end{array}$ \\
\hline & & Argumentativo & Convencer \\
\hline & $\begin{array}{l}\text { Situación } \\
\text { sociocomunicativa }\end{array}$ & $\begin{array}{ll}\text { - Interlocutores } \\
\text { receptor(es) } \\
\text { - Circunstancias } \\
\text { - Intención com } \\
\text { - Tema (mensaje }\end{array}$ & $\begin{array}{l}\text { emisor(es) } \\
\text { (contexto) } \\
\text { unicativa } \\
\text { ) }\end{array}$ \\
\hline & $\begin{array}{l}\text { Contexto } \\
\text { sociocultural }\end{array}$ & $\begin{array}{l}\text { Factores externos } \\
\text { producción del texto }\end{array}$ & que afectan a la \\
\hline Formal & Convenciones & & \\
\hline
\end{tabular}

Algunos ejemplos son los siguientes:

\begin{tabular}{|lr|l|}
\hline $\begin{array}{l}\text { Textos médicos dirigidos a } \\
\text { profesionales sanitarios }\end{array}$ & - Protocolos de ensayos clínicos \\
& - Manuales para investigadores \\
& - Monografías de producto \\
& - Artículos originales \\
& - Artículos de revisión \\
& - Material promocional \\
\hline $\begin{array}{l}\text { Textos médicos dirigidos a } \\
\text { agencias reguladoras }\end{array}$ & $\begin{array}{l}\text { - Informe final de un ensayo clínico } \\
\text { - Documento técnico común (DTC) } \\
\text { - Ficha técnica }\end{array}$ \\
\hline $\begin{array}{l}\text { Textos médicos dirigidos a } \\
\text { pacientes y familiares }\end{array}$ & $\begin{array}{l}\text { - Consentimiento informado } \\
\text { - Folletos de información para pacientes } \\
\text { - Prospectos }\end{array}$ \\
\hline $\begin{array}{l}\text { Textos médicos dirigidos a } \\
\text { delegados de ventas }\end{array}$ & - Manuales de formación \\
\hline $\begin{array}{l}\text { Textos médicos dirigidos a } \\
\text { periodistas y profesionales de la } \\
\text { comunicación }\end{array}$ & $\begin{array}{l}\text { - Notas de prensa } \\
\text { - Dossiers de prensa }\end{array}$ \\
\hline
\end{tabular}




\section{Población de estudio y corpus textual}

\section{I. Delimitación de la población de estudio}

Para realizar este estudio, hemos acudido a un total de doce personas que tienen distinta relación con los textos médicos y la lengua alemana: a) médicos que saben alemán; b) traductores no especializados en traducción médica; c) filólogos o germanistas; d) población con nivel alto del idioma, pero carentes de formación traductológica y conocimientos médicos.

\subsection{Corpus textual}

Para llevar a cabo este estudio hemos seleccionado distintos de textos médicos, en función del receptor y el grado de dificultad (divulgativo, semiespecializado y especializado). Son los siguientes:

\section{TO I: Alzheimer: eine Form der Demenz}

Die nach dem Nervenarzt Alois Alzheimer (1864 - 1915) benannte Krankheit ist seit rund 100 Jahren bekannt. Sie ist eine Form der Demenz, also ein Verfall der geistigen Leistungsfähigkeit, und tritt meist erst im Alter auf. Angesichts der steigenden Lebenserwartung nimmt das Risiko, daran zu erkranken, zu - in Deutschland sind derzeit bis zu I,6 Millionen Menschen von Demenz betroffen, der Großteil davon leidet an Alzheimer.

Man schätzt, dass rund $5 \%$ der über Sechzigjährigen und $20 \%$ der über Achtzigährigen an der Alzheimer-Krankheit leiden. Nach den Schlaganfällen steht sie an zweiter Stelle der häufigsten schweren Hirnfunktionsstörungen im Alter. Seltene, vererbliche Formen können allerdings auch Menschen ab dem dreißigsten Lebensjahr

[Alzheimer: Una forma de demencia

Conocida desde hace aproximadamente 100 años, después de que el neurólogo Alois Alzheimer (1864-1915) le acuñara el nombre. Es una forma de demencia, que implica una disminución de la capacidad mental y por lo general, sólo se produce en la vejez. Dado el aumento de la esperanza de vida, se incrementa el riesgo de sufrirla- en Alemania son cerca de los 1,6 millones de personas afectadas por la demencia, la mayoría de ellos padecen de Alzheimer.

Se estima que alrededor del $5 \%$ de las personas mayores de 60 años y el $20 \%$ de las personas mayores de 80 años sufren de Alzheimer.

Después del Ictus, es el segundo trastorno cerebral grave más común en la vejez. En raras ocasiones, formas hereditarias podrían incluso afectar también a personas a partir de los 30 años.] 
TO 2: Arbeitsunfähigkeitsbescheinigung

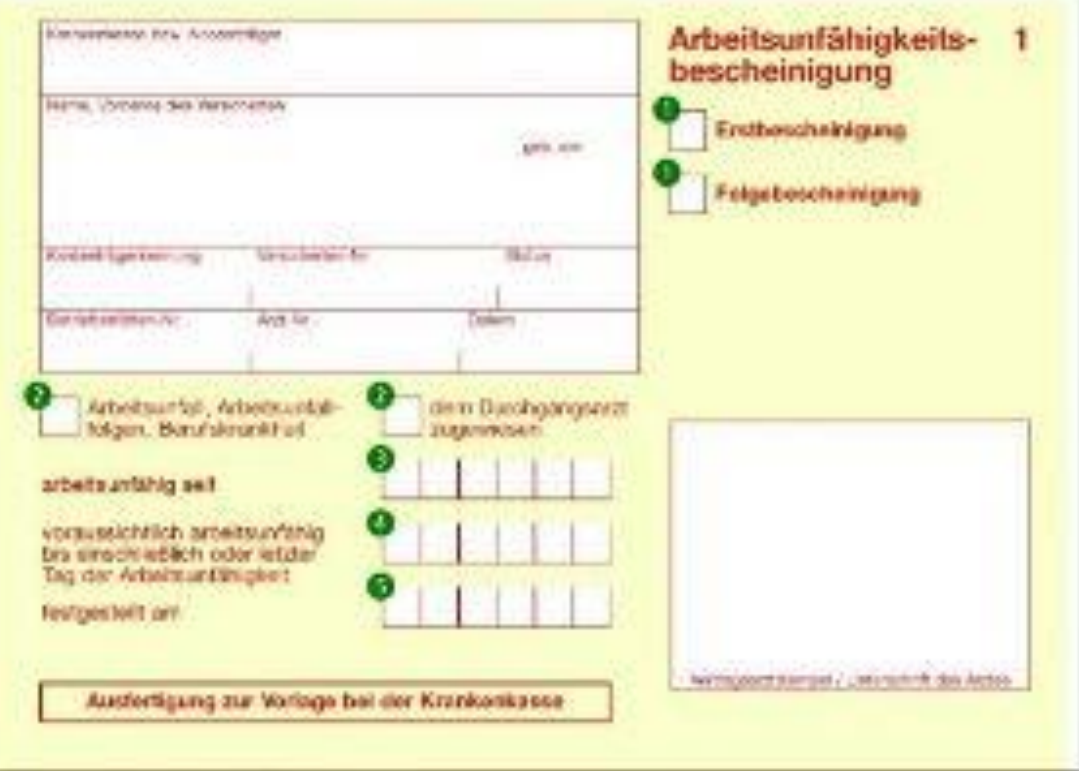

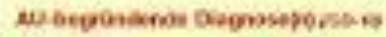

G $\boldsymbol{C}^{\text {rition }}$

$\boldsymbol{\theta}^{\mathrm{nin}}$

$0^{-5 \times \operatorname{sen}}$

$6^{\cos 2 \cos }$

$6^{-10-6 \pi n}$

o

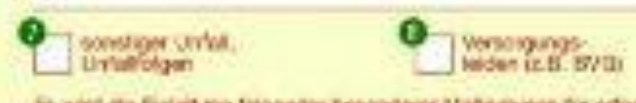

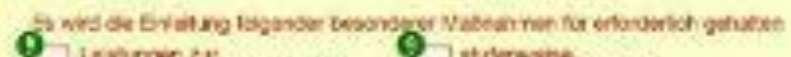

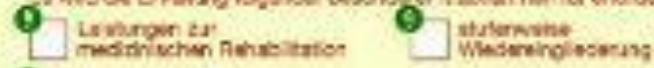

Q. serolos

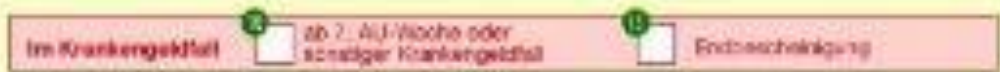

Wimatim 
[TM 2. Certificado de incapacidad laboral

Certificado de incapacidad laboral

I. Primer certificado

I. Segundo certificado

Seguro médico con respecto al sujeto pasivo de las costas

Nombre y apellidos del asegurado

Nacido en

Identificación del sujeto pasivo de las costas

Número del asegurado

Status

Número local de la empresa

Número del médico

Fecha

Firma del médico

2. Accidente laboral, consecuencias del accidente laboral, enfermedad causada por el trabajo

2. médico de paso asignado

3. inválido desde

4. Probablemente no puede trabajar hasta e incluyendo o el último día de incapacidad

5. diagnosticado el

Copiar para su presentación al seguro médico

TO 3: Gebrauchsinformation: Information für anwender Maxim ${ }^{\circledR} 0,03 \mathrm{mg} / 2 \mathrm{mg}$, überzogene Tablette.

Was ist Maxim und wofür wird es angewendet?

- Maxim ist ein Arzneimittel zur o Schwangerschaftsverhütung ("Pille"). o Behandlung von Frauen mit mittelschwerer Akne, die keine Gegenanzeigen für eine Therapie mit "Verhütungspillen" aufweisen, und nach Versagen von geeigneten lokalen Behandlungen. 
- Jede der 2I Filmtabletten enthält eine geringe Menge der weiblichen Geschlechtshormone Ethinylestradiol und Dienogest.

- "Pillen", die zwei Hormone enthalten, werden als "Kombinationspillen" bezeichnet.

- In klinischen Prüfungen wurde belegt, dass Maxim bei Frauen, bei denen eine verstärkte Wirkung von männlichen Hormonen (so genannte "Androgene" zum Auftreten von Akne führt, eine Besserung dieser Erscheinungen bewirkt.

[TO 3. Prospecto: información de uso. Maxim $0,03 \mathrm{mg} / 2 \mathrm{mg}$, comprimido recubierto

Etinilestradiol / Dienogest

¿Qué es Maxim y para qué se utiliza?

- Maxim es un medicamento para:

la anticoncepción o ( "Píldora"),

el tratamiento de las mujeres con acné moderado que no tienen contraindicaciones para la terapia con "píldoras anticonceptivas", y tras el fracaso de los tratamientos locales adecuados.

- Cada uno de los 21 comprimidos que contienen una pequeña cantidad de las hormonas sexuales femeninas etinilestradiol y dienogest.

- Estas "pastillas", que contienen dos hormonas, se llaman "píldoras combinadas".

- En los ensayos clínicos se demostró que Maxim en las mujeres, en los que un efecto mejorado de hormonas masculinas (llamada " andrógenos " conduce a la aparición de acné, provoca una mejora en los síntomas].

TO 4. Erforderlichkeit der Einwilligung in einen ärztlichen Eingriff sowie Einholung einer betreuungsgerichtlichen Genehmigung.

I. Jeder ärztliche Eingriff bedarf der Einwilligung durch den betroffenen Patienten.

2. Die Geschäftsfähigkeit des/der Betroffenen ist nicht Voraussetzung für ihre/seine Einwilligungsfähigkeit.

3. Bei seiner Entscheidung an Stelle des einwilligungsunfähigen Betroffenen muss sich der Betreuer (Bevollmächtigte) zuallererst nach dem Willen des 
Betroffenen richten, wenn dieser bekannt ist, weil der Betroffene ihn bereits früher schriftlich in einer Patientenverfügung geäußert hat.

4. Besonderheiten gelten bei der Einwilligung/Nichteinwilligung des Betreuers (Bevollmächtigten) oder dem Widerruf der Einwilligung des Betreuers (Bevollmächtigten) für den einwilligungsunfähigen Betroffenen, wenn es um besonders schwerwiegende ärztliche Eingriffe geht.

5. Eine ärztliche Behandlung darf immer nur so weit gehen, wie die Einwilligung reicht. Wird die Einwilligung widerrufen, hat die weitere Behandlung zu unterbleiben.

6. Für Schwangerschaftsabbrüche und Organspenden (nach Hirntod) sind weitere Vorschriften zu beachten.

[TM 4. La necesidad del consentimiento informado tanto en una intervención médica como para obtener asistencia judicial

I. Todas las intervenciones médicas requieren el consentimiento del paciente.

2. La capacidad legal del paciente no condiciona su capacidad de consentimiento.

3. En caso de que el paciente sea incapaz de dar su consentimiento, su representante legal (capaz de decidir por él) debe tomar la decisión basándose en la voluntad del paciente, siempre que ésta haya sido anteriormente reflejada en un testamento vital.

4. Cuando se trate de una intervención médica de mayor gravedad y el paciente se encuentre indispuesto, se aplicarán reglas específicas sobre el consentimiento (o no consentimiento) del representante legal y sobre la revocación del consentimiento del representante legal.

5. Un tratamiento médico no puede exceder a un consentimiento. Si se revoca el consentimiento, el tratamiento debe cesar por igual.

6. Para casos de interrupción del embarazo y donación de órganos (tras muerte cerebral) se aplicarán diferentes reglas.]

\section{TO 5. Entzündliche Wirbelsäulenerkrankungen Spondylitis}

Unter einer Spondylitis versteht man eine Entzündung des Wirbelkörpers. Ist das Bandscheibengewebe mitbetroffen, wird von einer Spondylodiszitis gesprochen.

Ursache 
Die Ursache der Spondylitis oder der Spondylodiszitis ist meist eine bakterielle Infektion. Dabei unterscheidet man unspezifische bakterielle Spondylitiden von der spezifischen Spondylitis, die bei einer Tuberkulose auftritt. Unspezifische Spondylitiden können hämatogen oder postoperativ entstehen.

\section{Symptomatik}

Die Symptomatik der Spondylitis besteht in Fieber und einer Leukozytose mit Erhöhung der Blutsenkungsgeschwindigkeit. Frühzeitig treten Rückenschmerzen im betroffenen Wirbelsäulenabschnitt auf, die mit einem ausgeprägten Klopfschmerz und Erschütterungsschmerz einhergeht. Durch die Destruktion des Wirbelkörpers treten Wirbelsäulenverkrümmungen ein (Skoliose, Gibbus). Schließlich kann es zur neurologischen Beteiligung mit radikulären Erscheinungen oder einer Querschnittsymptomatik kommen. Differentialdiagnostisch muß ein tumoröser Prozeß ausgeschlossen werden.

[TM 5. Enfermedades inflamatorias de la columna vertebral

Espondilitis

Bajo el término de espondilitis nos referimos a una inflamación del cuerpo vertebral. Si también se afecta el tejido del disco vertebral hablamos de espondilodiscitis.

\section{Causa}

La causa de la espondilitis o espondilodiscitis es generalmente una infección bacteriana. Existen diferencias entre espondilitis causadas por bacterias inespecíficas y específicas, como la producida por la bacteria de la tuberculosis. La causa de las espondilitis inespecíficas pueden ser la vía hematógena o postquirúrgica.

\section{Sintomatología}

Los síntomas de la espondilitis consisten en fiebre y leucocitosis con aumento de la velocidad de sedimentación globular (VSG). Primero aparece un dolor de espalda en el segmento espinal afectado, que se asocia con un dolor punzante y vibratorio. Consecuencia de la destrucción de los cuerpos vertebrales se modifica la curvatura de la columna que se manifiesta mediante escoliosis o giba. Por último, puede haber afectación neurológica con síntomas radiculares o paraplejia. En el diagnóstico diferencial hay que excluir un proceso tumoral. 


\section{Análisis: errores de traducción}

TM I: Alzheimer: Una forma de demencia

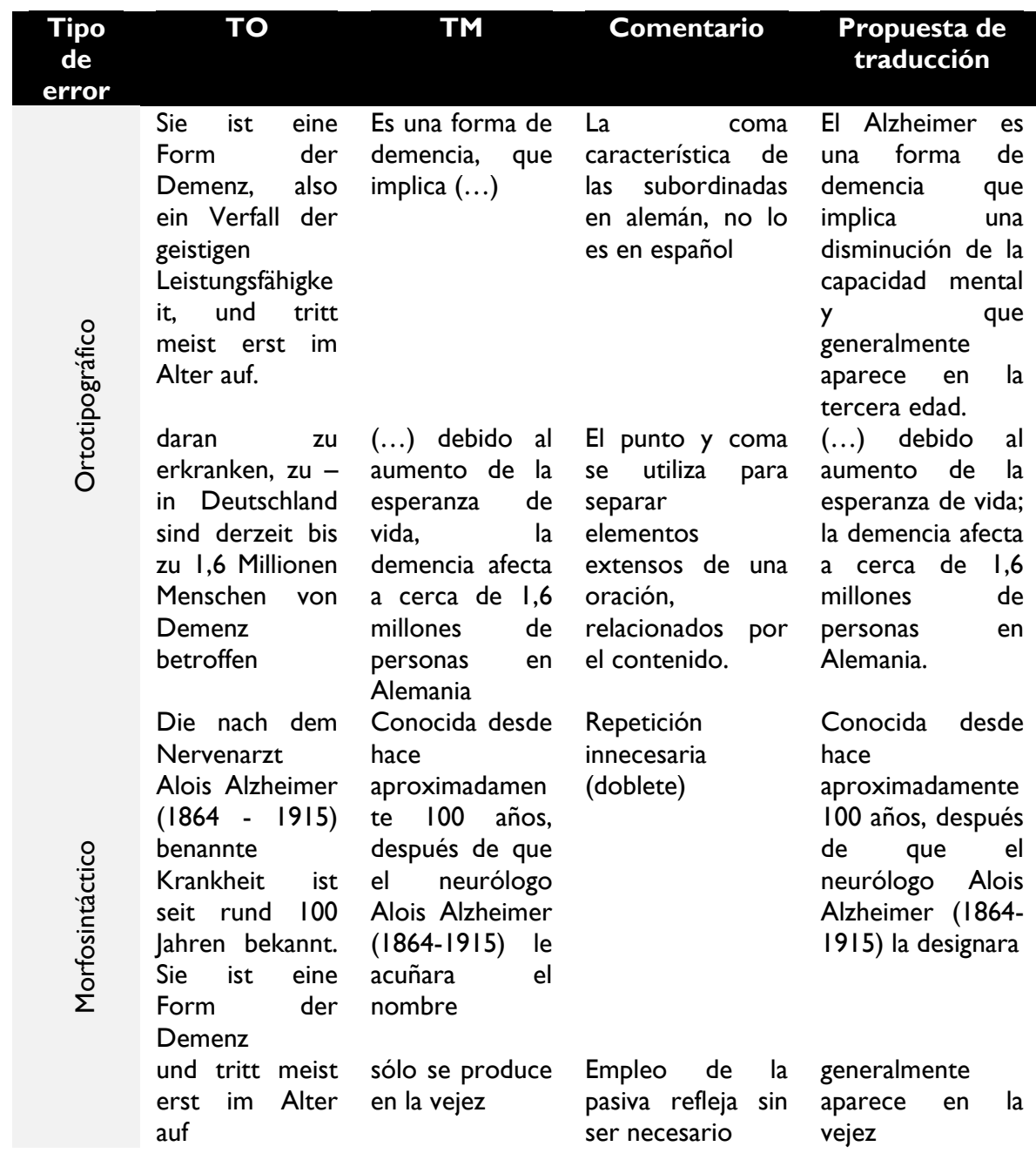




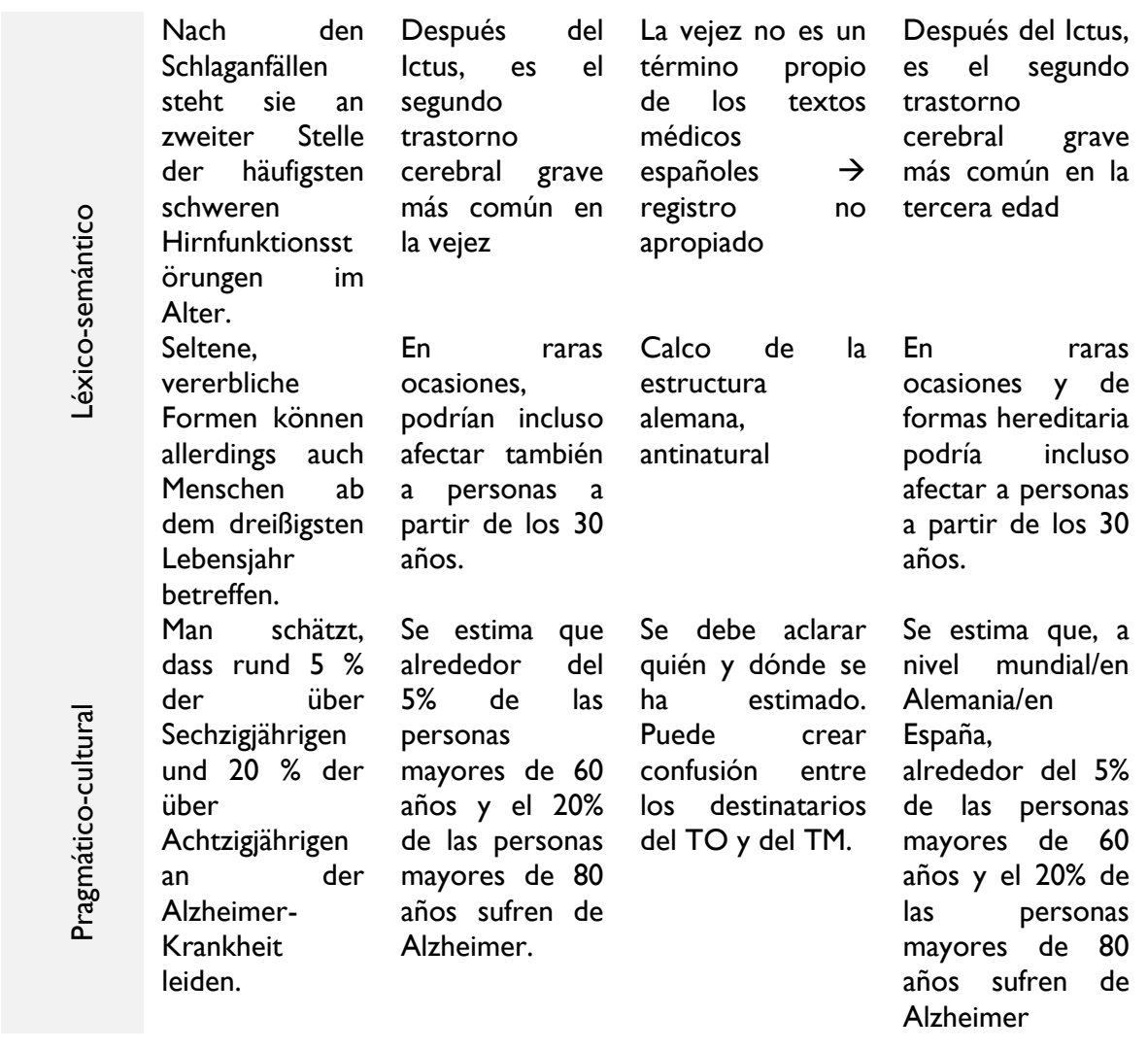


TM 2: Certificado de incapacidad laboral

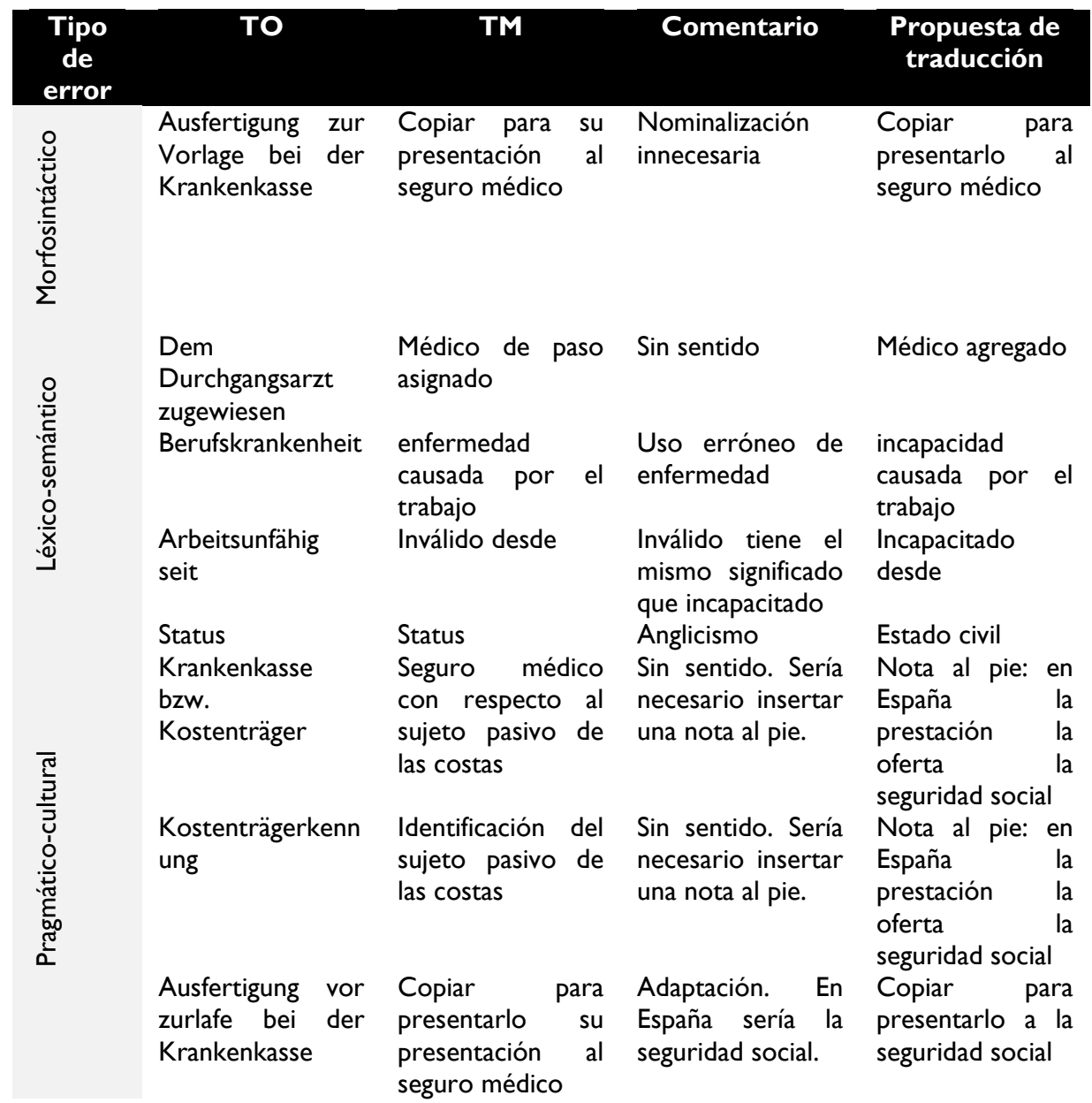


TM 3: Información de uso. Maxim 0,03 mg / 2 mg, comprimido recubierto

\begin{tabular}{|c|c|c|c|c|}
\hline $\begin{array}{l}\text { Tipo } \\
\text { de } \\
\text { error }\end{array}$ & TO & TM & Comentario & $\begin{array}{l}\text { Propuesta de } \\
\text { traducción }\end{array}$ \\
\hline 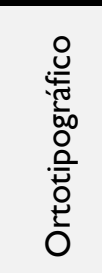 & $\begin{array}{l}\text { "Kombinationspill } \\
\text { en" }\end{array}$ & $\begin{array}{l}\text { "píldoras } \\
\text { combinadas" }\end{array}$ & $\begin{array}{l}\text { Comillas } \\
\text { españolas }\end{array}$ & $\begin{array}{l}\text { «píldoras } \\
\text { combinadas» }\end{array}$ \\
\hline 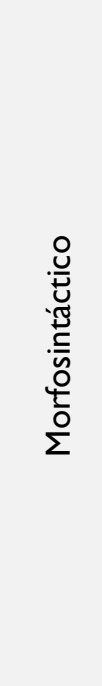 & $\begin{array}{l}\text { Behandlung von } \\
\text { Frauen mit } \\
\text { mittelschwerer } \\
\text { Akne, die keine } \\
\text { Gegenanzeigen } \\
\text { für eine Therapie } \\
\text { mit } \\
\text { "Verhütungspillen } \\
\text { " aufweisen, und } \\
\text { nach Versagen } \\
\text { von geeigneten } \\
\text { lokalen } \\
\text { Behandlungen. }\end{array}$ & $\begin{array}{l}\text { El tratamiento } \\
\text { de las mujeres } \\
\text { con acné } \\
\text { moderado que } \\
\text { no tienen } \\
\text { contraindicaci } \\
\text { ones para la } \\
\text { terapia con } \\
\text { "píldoras } \\
\text { anticonceptiva } \\
\text { s", y tras el } \\
\text { fracaso de los } \\
\text { tratamientos } \\
\text { locales } \\
\text { adecuados. }\end{array}$ & Sinsentido & $\begin{array}{l}\text { Tratamiento del } \\
\text { acné } \\
\text { moderado a } \\
\text { grave en } \\
\text { mujeres que no } \\
\text { tienen } \\
\text { contraindicacion } \\
\text { es en el uso de } \\
\text { anticonceptivos, } \\
\text { cuando el } \\
\text { tratamiento con } \\
\text { los } \\
\text { medicamentos } \\
\text { adecuados de } \\
\text { uso cutáneo ha } \\
\text { resultado } \\
\text { ineficaz. }\end{array}$ \\
\hline 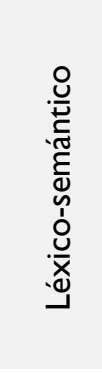 & $\begin{array}{ll}\text { bei denen } & \text { eine } \\
\text { verstärkte } & \\
\text { Wirkung } & \text { von } \\
\text { männlichen } & \\
\text { Hormonen } & \text { (so } \\
\text { genannte } & \\
\text { "Androgene" } & \text { zum } \\
\text { Auftreten } & \text { von } \\
\text { Akne führt } & \end{array}$ & $\begin{array}{l}\text { en los que el } \\
\text { efecto } \\
\text { mejorado de } \\
\text { las hormonas } \\
\text { masculinas }\end{array}$ & Falso sentido & $\begin{array}{l}\text { en los que el } \\
\text { efecto mayor de } \\
\text { las hormonas } \\
\text { masculinas }\end{array}$ \\
\hline
\end{tabular}


TM 4: La necesidad del consentimiento informado tanto en una intervención médica como para obtener asistencia judicial.

\begin{tabular}{|c|c|c|c|c|}
\hline $\begin{array}{l}\text { Tipo } \\
\text { de } \\
\text { error }\end{array}$ & TO & TM & Comentario & $\begin{array}{l}\text { Propuesta de } \\
\text { traducción }\end{array}$ \\
\hline 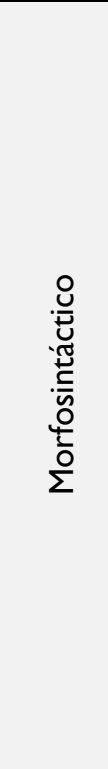 & $\begin{array}{l}\text { 5. Ich bin } \\
\text { einverstanden, } \\
\text { daß meine im } \\
\text { Rahmen der } \\
\text { klinischen } \\
\text { Prüfung } \\
\text { aufgezeichnete } \\
n \\
\text { Krankheitsdat } \\
\text { en zur } \\
\text { Überprüfung } \\
\text { an das } \\
\text { ethische dos } \\
\text { Komitee des } \\
\text { Kantons } \\
\text { Solothurn } \\
\text { weitergegeben } \\
\text { werden } \\
\text { können }\end{array}$ & $\begin{array}{lr}5 . \quad \text { Yo estoy } \\
\text { conforme con } \\
\text { que en la } \\
\text { investigación de } \\
\text { mi cuadro } \\
\text { clínico re } \\
\text { graben los datos } \\
\text { de ra } \\
\text { enfermedad la } \\
\text { para transmitir } \\
\text { el chequeo al } \\
\text { comité ético } \\
\text { Kanon } \\
\text { Solothum. }\end{array}$ & $\begin{array}{lr}\text { En } & \text { español } \\
\text { queda } & \text { muy } \\
\text { forzado el uso } \\
\text { del } & \text { sujeto } \\
\text { gramatical, por } \\
\text { lo } & \text { que } \\
\text { procedería usar } \\
\text { un } \\
\text { elíptico. }\end{array}$ & $\begin{array}{lr}\text { 5. Estoy conforme } \\
\text { con que en la } \\
\text { investigación de } \\
\text { mi cuadro clínico } \\
\text { se graben los } \\
\text { datos de la } \\
\text { enfermedad para } \\
\text { transmitir el } \\
\text { chequeo al al } \\
\text { comité ético } \\
\text { Kanon Solothum. }\end{array}$ \\
\hline 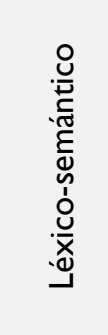 & $\begin{array}{l}\text { Besonderheite } \\
\mathrm{n} \text { gelten bei } \\
\text { der } \\
\text { Einwilligung/Ni } \\
\text { chteinwilligung } \\
\text { des Betreuers } \\
\text { (Bevollmächtig } \\
\text { ten) (...) }\end{array}$ & $\begin{array}{l}\text { En caso de que } \\
\text { el paciente sea } \\
\text { incapaz de dar } \\
\text { su } \\
\text { consentimiento } \\
(\ldots)\end{array}$ & $\begin{array}{l}\text { Incapaz es un } \\
\text { término } \\
\text { erróneo en este } \\
\text { contexto }\end{array}$ & $\begin{array}{l}\text { En caso de que el } \\
\text { paciente esté } \\
\text { incapacitado para } \\
\text { dar su } \\
\text { consentimiento } \\
(\ldots)\end{array}$ \\
\hline 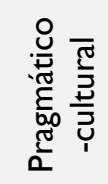 & - & - & - & - \\
\hline
\end{tabular}


TM 5: Enfermedades inflamatorias de la columna vertebral. Espondilitis.

\begin{tabular}{|c|c|c|c|c|}
\hline $\begin{array}{l}\text { Tipo } \\
\text { de } \\
\text { error }\end{array}$ & TO & TM & Comentario & $\begin{array}{l}\text { Propuesta de } \\
\text { traducción }\end{array}$ \\
\hline . & $\begin{array}{l}\text { Ist das } \\
\text { Bandscheibenge } \\
\text { webe } \\
\text { mitbetroffen, } \\
\text { wird von einer } \\
\text { Spondylodiszitis } \\
\text { gesprochen }\end{array}$ & $\begin{array}{l}\text { Si también se } \\
\text { afecta el tejido del } \\
\text { disco vertebral } \\
\text { hablamos de } \\
\text { espondilodiscitis. }\end{array}$ & $\begin{array}{l}\text { Uso innecesario } \\
\text { de la voz pasiva }\end{array}$ & $\begin{array}{l}\text { Si también afecta el } \\
\text { tejido del disco } \\
\text { vertebral hablamos } \\
\text { de espondilodiscitis }\end{array}$ \\
\hline $\begin{array}{l}\text { L } \\
\text { to } \\
\Sigma\end{array}$ & $\begin{array}{l}\text { Unspezifische } \\
\text { Spondylitiden } \\
\text { können } \\
\text { hämatogen oder } \\
\text { postoperativ } \\
\text { entstehen }\end{array}$ & $\begin{array}{l}\text { La causa de las } \\
\text { espondilitis } \\
\text { inespecíficas } \\
\text { pueden ser la vía } \\
\text { hematógena o } \\
\text { postquirúrgica. }\end{array}$ & $\begin{array}{l}\text { No } \\
\text { concordancia en } \\
\text { el número del } \\
\text { sujeto y el } \\
\text { verbo }\end{array}$ & $\begin{array}{lr}\text { La causa de las } \\
\text { espondilitis } \\
\text { inespecíficas puede } \\
\text { ser la vía } \\
\text { hematógena } \\
\text { postquirúrgica. }\end{array}$ \\
\hline 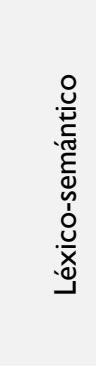 & $\begin{array}{l}\text { Schließlich kann } \\
\text { es zur } \\
\text { neurologischen } \\
\text { Beteiligung mit } \\
\text { radikulären } \\
\text { Erscheinungen } \\
\text { oder einer } \\
\text { Querschnittsym } \\
\text { ptomatik } \\
\text { kommen. }\end{array}$ & $\begin{array}{l}\text { Por último, puede } \\
\text { haber una } \\
\text { afectación } \\
\text { neurológica } \\
\text { síntomas con } \\
\text { radiculares } \\
\text { paraplejia. }\end{array}$ & $\begin{array}{l}\text { El verbo no se } \\
\text { adapta } \\
\text { contexto }\end{array}$ & $\begin{array}{l}\text { Por último, puede } \\
\text { surgir una } \\
\text { afectación } \\
\text { neurológica con } \\
\text { síntomas radiculares } \\
\text { o paraplejia. }\end{array}$ \\
\hline
\end{tabular}

\section{Resultados}

Como hemos podido comprobar en las tablas precedentes, la especificidad del lenguaje médico se encuentra principalmente en la terminología, aunque también en el estilo y la sintaxis. Para analizar los distintos resultados, tenemos en cuenta la población que ha realizado las traducciones, y así en cada gráfico, establecemos los siguientes grupos:

Grupo A: licenciados en Filología Alemana

Grupo B: personas bilingües (es-de)

Grupo C: médicos con dominio del alemán (BI) 
Grupo D: hispanohablantes no traductores con dominio del alemán (B2)

Grupo E: estudiantes de $4^{\circ}$ de Traducción e Interpretación

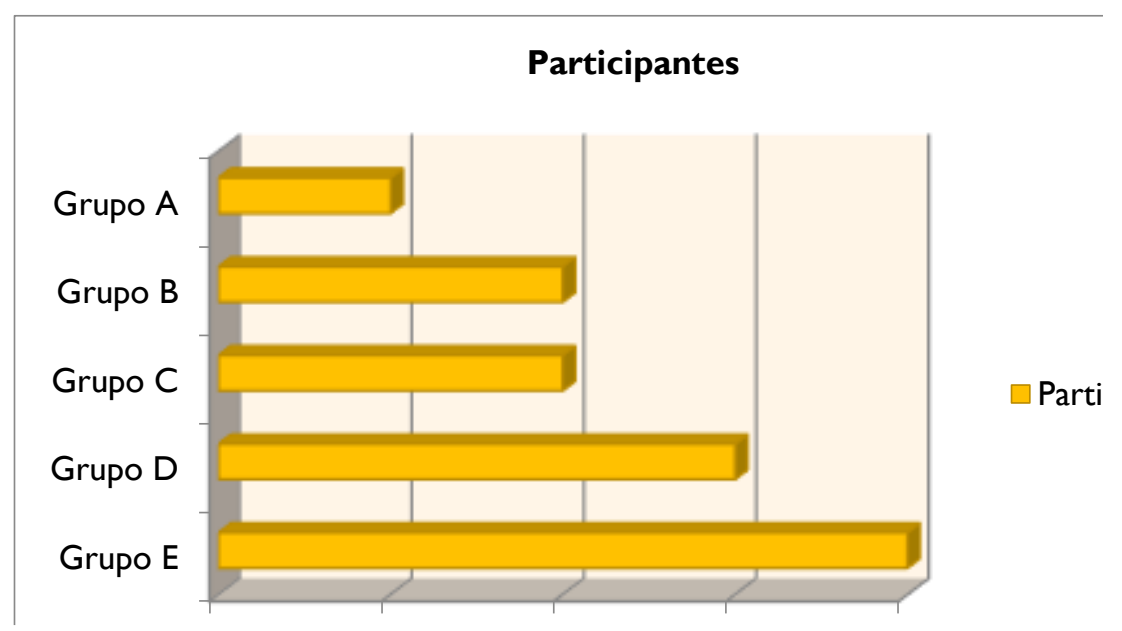

En lo relativo a los errores de traducción, cada grupo de población viene representado en el siguiente gráfico:

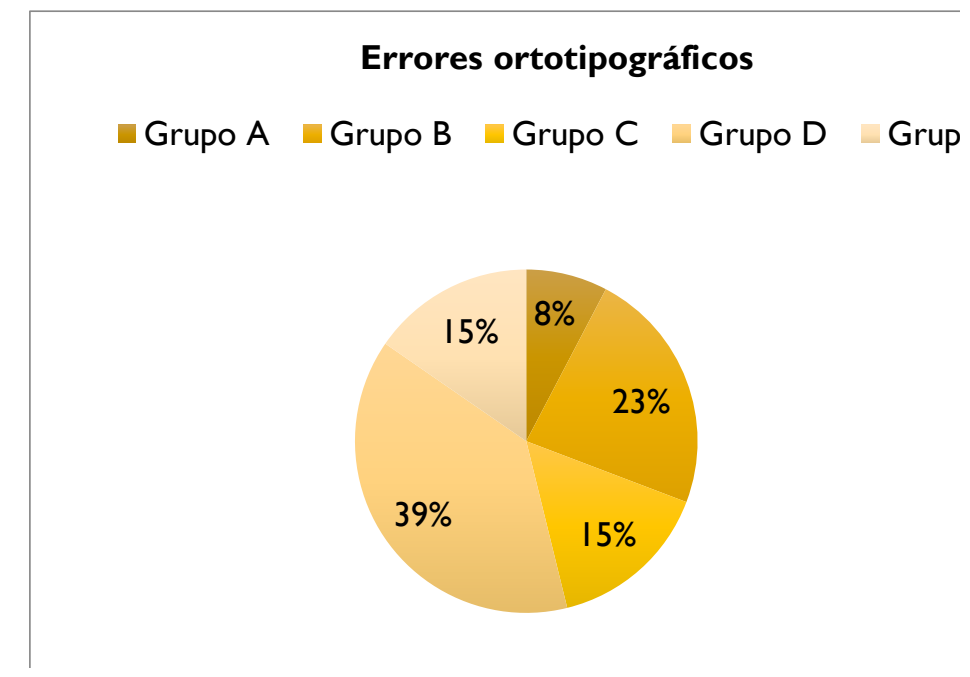


En primer lugar podemos observar que el grupo $D$ es el que más errores comete, siendo los estudiantes de $4^{\circ}$ año de traducción los que mejor posición obtienen en este baremo. En segundo lugar estaría el grupo B, los bilingües de español y alemán, seguido del grupo $C$ y $A$. Estos resultados quizás se deben al empleo de la lengua alemana usualmente de forma hablada. La puntuación, concretamente, es muy diferente a la nuestra, sobre todo en oraciones compuestas y subordinadas, por lo que lleva al hablante de alemán a cometer errores a pesar de tener un alto nivel al hablarlo.

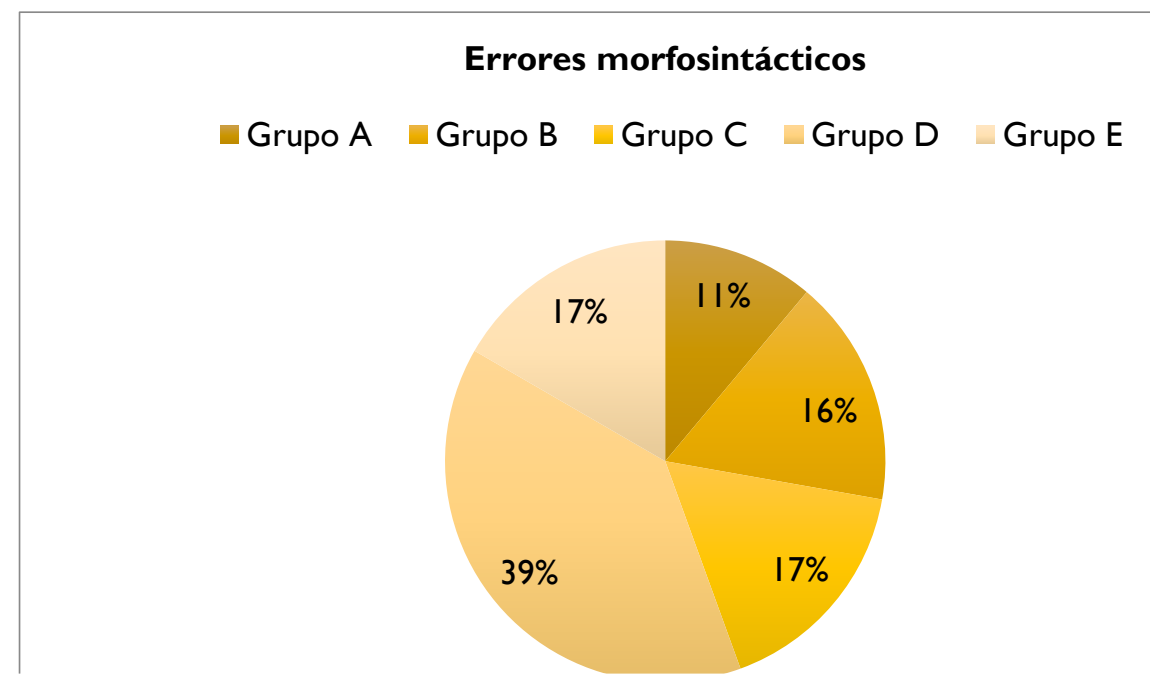

En el nivel morfosintáctico, el grupo C, los médicos, es el que más errores ha cometido, seguido del grupo D. Los errores más comunes son el uso de la voz pasiva, muy común en los textos médicos ingleses y alemanes que no es muy habitual en los textos españoles. La concordancia entre sujeto y verbo también ha causado algunos errores, sobre todo, en frases extensas y complejas. Sin embargo, la mayoría de los sometidos a estudio ha elaborado algún sin sentido, consecuencia de la compleja gramática y terminología por las que se caracteriza la traducción médica. 


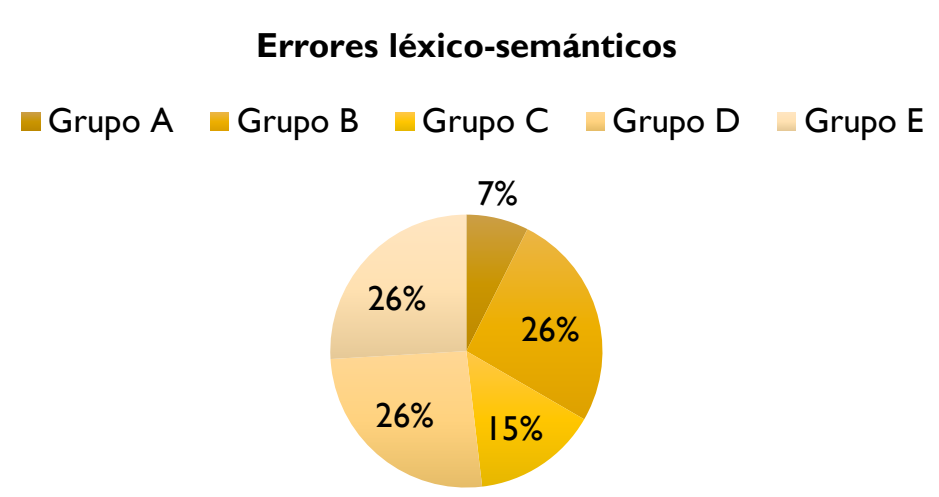

La terminología es el principal problema que se le ha planteado a los sujetos estudiados. Observamos que el grupo B, el grupo D y el grupo E, los estudiantes de $4^{\circ}$ año de traducción, coinciden en el número de errores. Sin embargo, conforme al número de personas correspondientes a cada grupo, los bilingües son los que un mayor número de errores han cometido. El desconocimiento del texto que se debe traducir ha demostrado la importancia de la terminología médica, obteniendo así los profesionales sanitarios una mejor puntuación.

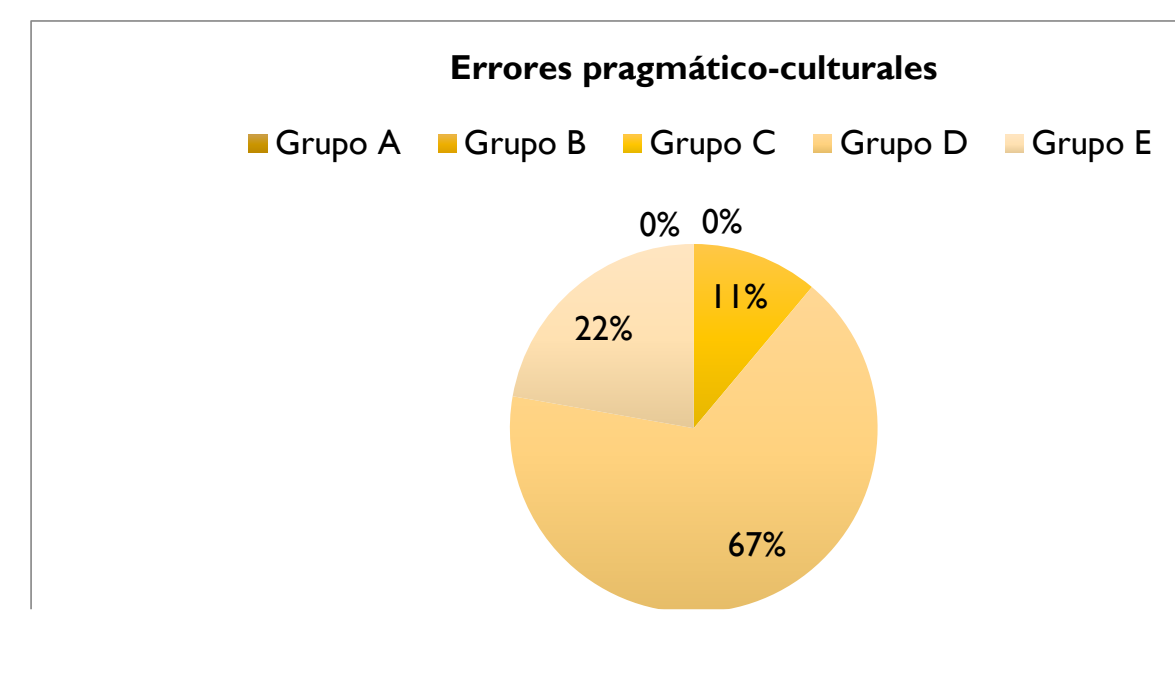


Este tipo de errores cobran una gran importancia a la hora de traducir y adaptar textos a la lengua meta. Los grupos A y B carecen de este tipo de errores, quizás porque los textos no lo exigían. En el caso del grupo $D$, se enfrentaban a textos específicos que determinan rasgos de los sistemas sanitarios de ambos países, por lo que necesita una breve aclaración. Con respecto a los grupos $\mathrm{C}$ y $\mathrm{E}$, los errores han sido anglicismos y otros de carácter leve, como por ejemplo el empleo de comillas inglesas o españolas o la traducción de términos que son más frecuentes en América Latina que en España.

\section{Propuesta de metodología para la traducción de textos biosanitarios}

El método de adquisición de la terminología que proponemos en el presente trabajo parte de la traducción. Este proceso se caracteriza por la capacidad de análisis y de reflexión, la aplicación a situaciones prácticas, la rigurosidad y la curiosidad intelectual. Al realizar este proceso, el traductor desarrolla sus capacidades lingüísticas en todos los aspectos, tanto en la gramática como en el léxico. Estos deben tener un conocimiento íntegro de la lengua, pero no siempre es así al tratarse de terminología especializada.

Por ello se debe realizar un análisis preciso a nivel sintáctico del texto al que nos enfrentamos, donde encontraremos palabras, nombres propios y términos, siendo estos últimos característicos del lenguaje artificial. El lenguaje científico, el médico particularmente, proviene mayormente del griego y del latín, lo que hace que un gran número de términos compartan raíz léxica, sufijos o prefijos. El desarrollo del proceso traductor, puntualizando qué función tiene cada unidad léxica en la oración y reconociendo el significado y la formación de la terminología, facilitaría la adquisición de dichos conocimientos.

Cabe destacar que la mayoría de los textos especializados, en este caso los médicos, abordan un tema en concreto, sobre todo los textos con un rango de especialización más alto, como por ejemplo un libro de fisioterapia o un artículo destinado a la comunidad científica sobre oncología. De hecho, podemos ver el resultado en el estudio realizado ya que los errores léxico-semánticos detectados no suponen una amenaza para la coherencia y el sentido del texto. Por ello, nos atrevemos a proponer el siguiente método para el aprendizaje de la terminología especializada en el setor biosanitario, así como para la adquisición de competencias que propicien la correcta traducción de los textos:

- Lectura del texto origen (TO)

- Documentación sobre el tema 
- Reconocimiento de palabras, nombres propios y términos especializados

- Análisis de la raíz verbal, prefijos y sufijos de los términos especializados

- Establecimiento de la relación entre los términos

- Búsqueda del significado de uno de los términos e intentar traducir el resto gracias a la similitud de ambas unidades

- Verificación de que la traducción de los términos es correcta, para afianzar la coherencia del texto

- Resaltar y memorizar los términos traducidos, teniendo en cuenta el contexto en el que se emplean y la formación de los mismos.

\section{Conclusiones}

Lo expuesto en las páginas precedentes nos llevan a las siguientes conclusiones:

I. Realizar una distinción entre adquisición de lenguas con fines genéricos y adquisición con fines específicos es algo muy frecuente en el momento de aprender una segunda lengua. La primera se asocia con los programas cursados por estudiantes de la lengua extranjera con el fin de poder mantener una conversación llana. Es la impartida en los centros escolares, escuelas de idiomas y academias. La última se relaciona con los programas de idiomas destinados a grupos de estudiantes específicos, como es el caso del presente trabajo.

2. La finalidad principal de la traducción es superar las barreras lingüísticas y culturales que surgen entre países de diferentes lenguas. Por lo que, una traducción no debe parecer artificial o confusa, sino que debe resultar un texto natural que se adapte a las necesidades de los destinatarios. Sin embargo, para poder otorgar naturalidad a los documentos traducidos, debemos conocer previamente el léxico al que nos enfrentamos.

3. El establecimiento de una metodología clara para poder analizar la densidad léxica de un texto, así como el significado de cada uno de los términos que conforman el tecnolecto, es fundamental para la correcta comprensión del TO y la traslación posterior a la LM, sin que se produzcan errores de sentido o significado ni disonancias. 


\section{Referencias bibliográficas}

Balbuena, M. C. (2007). El léxico de la medicina: análisis contrastivo alemán-español orientado a la traducción. Cadernos Eborenses. Revista de Traduçao, Lingüística e Literatura I, 393-408.

Barros, M. (2002), Aspectos léxicos de la traducción especializada. En Garrido, A., $3^{\circ}$ Seminario de traducción e interpretación especializadas. Seminario llevado a cabo en el Instituto Cervantes de Nueva York. Recurso disponible en la red: http://www.apuntesonline.org/ponenciabarros.htm

Benavent, R.; Amador, R. (2002). Problemas del lenguaje médico actual (III) Gramática y estilo. En: Panace@, II (I): I8-23.

Cabré, M. T. (2002). Textos especializados y unidades de conocimiento: metodología y tipologización. En: GARCÍA, J. y FUENTES, M.T. (eds.). Texto, terminología y traducción. Salamanca, Ediciones Almar, 15-36.

Cobos, I. (2014). Traducción, ciencia y derecho. Skopos. Revista Internacional de Traducción e Interpretación, 4: 49-62.

Estopà, R.; Valero, A. (2002). Adquisición de conocimiento especializado y unidades de significación especializada en medicina. En: Panace@, Vol III (9-10): 7282.

Fluck, H. R. (1976). Fachsprachen. München: Francke Verlag.

Löning, P. (198I). Zur medizinischen Fachsprache., Muttersprache 91/I98I: 79-92.

López, C. I. (2000). Tipologías y géneros en la normalización terminológica y ortotipográfica de la traducción médica. Terminologie et traduction, 3, 95II5.

Martín-Jacob, E. F. (2005), Consideraciones sobre terminología y lexicografía médicas. Ars Médica. Revista de Humanidades, 4: 127-135.

Monalt i Resurecció, V. (2005). Manual de traducció cientificotècnica. Barcelona: EUMO.

Navarro, F. A. (2009). La precisión del lenguaje en la redacción médica. En RICOVILLADEMOROS, F. y ALFARO V., Cuadernos de la Fundación Dr. Antonio Esteve, 17, 89-94.

Navarro, F. A.; Hernández, F.; Rodríguez, L. (1994). Uso y abuso de la voz pasiva en el lenguaje médico escrito. En: Medicina Clínica, 103 (I2): 46I-464.

Ordóñez, A; García, C. (1989). Las metáforas médicas. En: Medicina Clínica.

Porep, R.; Steudel W. I. (1983). Medizinische Terminologie. Ein programmierter Kurs mit Kompendium zur Einführung in die me-dizinische Fachsprache. Stuttgart/Nueva York: Georg Thieme [I ${ }^{\mathrm{a}}$ edición: 1974].

Rodríguez-Perdomo, T. (20I2). La polisemia en la traducción jurídico-médica. En: Panace@, Vol. XIII (36): 32I-326. 
Van Hoof, H. (1986). Précis pratique de traduction médicale (anglais-français). París: Maloine (trad. al español de E. Ortega Arjonilla y otros.1999. Manual práctico de traducción médica, Granada, Comares).

Wulff, H. R. (2004). The Language of Medicine. Journal of the Royal Society of Medicine, 97(4): 187-188. 